\title{
QUALIDADE DO FISHBÚRGER DE CARNE MECANICAMENTE SEPARADA DE TILÁPIA DO NILO ADICIONADO DE FIBRA DE TRIGO E ÓLEO DE MILHO
}

\author{
THE FISH BURGER QUALITY OF MECHANICALLY RECOVERED MEAT FROM TILAPIA \\ USING ADDED WHEAT FIBRE AND CORN OIL
}

\author{
H. M. G. MÉLO ${ }^{1 *}$,S. M. R. GALVÃ̃ ${ }^{2}$, J. G. SILVA ${ }^{2}$, M. I. S. MACIEL ${ }^{2}$, R. T. MOREIRA ${ }^{3}$, \\ S. A. C. ANDRADE ${ }^{4}$, E. S. MENDES ${ }^{2}$
}

\begin{abstract}
RESUMO
Hambúrgueres foram elaborados manualmente com carne mecanicamente separada (CMS) de tilápia, em um planejamento fatorial 22 completo, visando determinar o efeito da fibra de trigo e óleo de milho no encolhimento e na capacidade de retenção de água. A melhor formulação obtida foi a interação de $1 \%$ de óleo de milho e $2,5 \%$ de fibra de trigo e como resposta $4,3 \%$ de encolhimento e $87 \%$ de capacidade de retenção de água. Na segunda etapa, a melhor formulação de CMS foi elaborada manualmente em quatro bateladas e submetidas às análises microbiológicas, físicoquímicas e sensorial, em triplicata. Os hambúrgueres encontravam-se dentro dos padrões permitidos pela legislação brasileira. A fibra de trigo e o óleo vegetal de milho podem ser utilizados na elaboração de fishbúrguer de CMS de tilápia, com excelente aceitação sensorial.
\end{abstract}

PALAVRAS-CHAVE: Análise descritiva quantitativa. Hambúrguer. Peixe.

\section{SUMMARY}

Fish burgers were made manually using mechanically recovered meat (MRM) from tilapia in a 22 full factorial design to determine the effect of wheat fibre and corn oil shrinkage on the water retention capacity of fish burgers. The best formulation was obtained using $1 \%$ corn oil and $2.5 \%$ wheat fibre, which resulted in a $4.3 \%$ shrinkage rate and $87 \%$ water retention capacity. In the second step, the best formulation was again prepared manually in four batches and subjected to bacteriological, physico-chemical and sensory tests in triplicate. The fish burgers were found to be within the standard microbiological and physical chemical parameters required by Brazilian law. Fibre from wheat and vegetable oil corn can be used to prepare fish burgers from MRM tilapia with excellent sensory acceptance.

KEY-WORDS: Quantitative descriptive analysis. Hamburger. Fish.

\footnotetext{
${ }^{1}$ Instituto Federal de Educação, Ciência e Tecnologia de Pernambuco, Brasil - Campus Barreiros. Barreiros - PE, Brasil, CEP: 55560-000 - Email: helidamelo3@ hotmail.com

${ }^{2}$ UFRPE - Universidade Federal Rural de Pernambuco. Recife, Pernambuco, Brasil.

${ }^{3}$ UFPB - Universidade Federal da Paraíba - João Pessoa, PB.

${ }^{4}$ UFPE - Universidade Federal de Pernambuco. Recife, PE.
} 


\section{INTRODUÇÃO}

A produção mundial de tilápia em 2012 foi de cerca de 4,0 milhões de toneladas (FITZSIMMONS, 2013). A produção dessa espécie ficou estimada em 2013 com mais de 4,0 milhões de toneladas (Global Aqualculture Production, 2013). No Brasil, a produção passou de 150 mil toneladas em 2010 para cerca de 240 mil toneladas em 2012 (BRASIL, 2012; WILD, 2013; SUSSEL, 2013). O pescado pode atender as necessidades nutricionais por ser um alimento de fácil digestão, com proteínas de alto valor biológico além de cálcio e fósforo, vitaminas A, D e complexo B (SIMÕES et al., 2004). No caso da tilápia do Nilo advinda da aqüicultura, a fração lipídica é rica em ácidos graxos poliinsaturados como o ômega podendo variar de 1,88 a $5,92 \%$ em filés (LEONHARDT et al., 2006).

A carne mecanicamente separada (CMS) pode ser utilizada na elaboração de produtos de alto valor agregado, atingindo determinados segmentos de mercado, ou para atender à necessidade social da demanda por proteína de origem animal de primeira qualidade com preço acessível (KUNH \& SMITH, 2002). Entretanto, a regulamentação para a CMS de peixe ainda não está em vigência, existindo uma proposta de alteração do Regulamento de Inspeção Industrial e Sanitária de Produtos de Origem Animal (RIISPOA). CMS de pescado é definida como sendo o produto congelado obtido do pescado descabeçado, eviscerado, limpo e separado mecanicamente dos músculos e estruturas inerentes a espécie como espinhas, ossos e pele, podendo ser lavada ou não, adicionada ou não de aditivos, seguido do nome da espécie de pescado que a caracterize, podendo ser obtida de carcaças espinhaços ou parte destes" (BRASIL, 2008). A CMS pode também ser elaborada a partir de diferentes espécies de peixes, inclusive as de baixo valor de mercado.

A CMS de pescado tem sido utilizada na elaboração de novos produtos como salsichas, nuggets e fishbúrgueres (VIEGAS \& OLIVEIRA, 2008). O teor lipídico dos alimentos, podem se maléficos à saúde, principalmente pelo colesterol contido. Existe hoje uma tendência da procura por produtos com teor lipídico reduzido ou então a substituição destes por ácidos graxos poliinsaturados (oléico) ou ácidos graxos poliinsaturados e sem colesterol. Neste sentido, óleos vegetais como os do milho, algodão e oliva como as salsichas (JIMENEZ-COLMENERO et al., 2001). O desenvolvimento de produtos cárneos com menor teor de gordura tem sido uma meta das indústrias, visando atender o mercado consumidor com alimentos com menor valor calórico (FIGUEREDO, et al., 2002).

A utilização de fibra alimentar na alimentação humana é nutricionalmente importante e influencia de forma positiva o processamento dos produtos. A fibra adicionada em produtos cárneos melhora o rendimento ao cozimento e aumenta a capacidade de retenção de água da carne, reduzindo o custo da formulação e aumentando a textura do alimento (CARBONELL et al., 2005). Desta forma, objetivou-se avaliar a CMS de tilápia como matéria-prima na elaboração de hambúrgueres, adicionados de fibra de trigo insolúvel e do óleo vegetal de milho, e verificar o efeito desses componentes sobre as características de qualidade do fishbúrguer. Com relação a utilização desses ingredientes na formulação é importante frisar que: existem muitos trabalhos utilizando óleo de milho e fibra de trigo, como produtos a partir de carne de frango. Todavia, não foi acusado registro desses ingredientes em CMS de tilápia.

\section{MATERIAL E MÉTODOS}

Para a elaboração do produto, foi adquirida a CMS de tilápia congelada, em pacotes de $2 \mathrm{~kg}$, de uma indústria de pescado situada no estado de Pernambuco. Os fishbúrgueres foram elaborados manualmente. A CMS foi descongelada durante 24 horas à temperatura de $5^{\circ} \mathrm{C}$. Os ingredientes utilizados foram iguais em todas formulações: proteína isolada de soja $(3,21 \%)$, fécula de mandioca $(1,60 \%)$, sal $(0,82 \%)$, condimentos (cebola, coentro, mostarda, noz moscada, cominho, gengibre, alho, $(1,64 \%))$, polifosfatos $(0,29 \%)$, fixador de cor $(0,51 \%)$, água $(11,28 \%)$ e sal de cura $(0,12 \%)$. O percentual de óleo de milho e da fibra de trigo variou de acordo com cada formulação (MOREIRA ET AL., 2006). A massa foi moldada e cada fishbúrguer foi embalado em filme de polietileno e congelado a $-18^{\circ} \mathrm{C}$. Posteriormente, foram realizadas as análises de encolhimento (Mansour \& Khalil, 1997) e Capacidade de Retenção de Água (CRA) (Hamm, 1960).

As análises bacteriológicas nas CMS e fishbúrgueres de tilápia foram contagens de Estafilococos coagulase positivo, número mais provável (NMP) de coliformes termotolerantes, pesquisa de Escherichia coli e Salmonella spp, (BRASIL, 2003). As análises de número mais provável de clostrídios sulfito redutores foram realizadas apenas na CMS, (Ministério da Agricultura Abastecimento e Reforma Agrária, Brasil, 1992). A formulação que apresentou as melhores respostas de acordo com o planejamento experimental $2^{2}$ quando comparada às demais foi novamente elaborada em quatro bateladas e submetida às análises bacteriológicas, físico-químicas e sensoriais em triplicata.

Foram retiradas amostras analíticas em triplicata da CMS e dos fishbúrgueres de cada batelada, para a determinação da composição centesimal, cálcio, fibra bruta e pH, (AOAC, 2006), carboidratos (ASCAR, 1985) e cor, através do colorímetro Minolta Color reader CR-400 e aferidas três medições em diferentes pontos do produto, do terço superior, médio e inferior.

Para realização da análise sensorial, esta pesquisa foi avaliada e aprovada pelo Comitê de Ética da Universidade de Pernambuco, com Registro (CEP/UPE) $\mathrm{N}^{0}$ 147/10. O estudo foi realizado conforme os preceitos da Resolução de número 196/96 do Conselho Nacional de Saúde. Os fishbúrgueres foram previamente grelhados em chapa aquecida untada com óleo vegetal. A cada um minuto foram virados, até apresentar aspecto de grelhado. O tempo total de grelha foi de nove minutos (ARISSETO \& POLLONIO, 2005). Sendo posteriormente realizada 
análise descritiva quantitativa (ADQ) (Stone \& Sidel, 1998). Os testes foram realizados em cabines individuais iluminadas com lâmpadas fluorescentes. As amostras foram casualizadas e testadas em todas as combinações entre os provadores. Para o teste de ADQ foram distribuídos previamente 119 questionários entre alunos e servidores da UFRPE. Destes foram selecionados 84 para o teste de percepção dos cinco sabores (salgado, doce, amargo, ácido e umami). Destes 84, 14 provadores foram selecionados. Nesses 14 foi realizado um treinamento para o desenvolvimento dos atributos do fishbúrguer de CMS de tilápia, sendo selecionados finalmente oito provadores para o teste de ADQ.

$O$ teste de aceitação global foi realizado em laboratório por 50 provadores não treinados utilizandose uma escala hedônica de 7 pontos, sendo 7 = "gostou muitíssimo" e 1 = desgostou muitíssimo", para os atributos de cor, uniformidade, aroma e sabor de peixe de água doce e condimento, maciez, suculência e qualidade global (STONE \& SIDEL 1998).

No teste de atitude de compra foi utilizada escala de 5 pontos, sendo: $5=$ "Compraria e $1=$ "jamais compraria". O teste foi realizado em laboratório e contou com a participação de 50 provadores não treinados (STONE \& SIDEL 1998).

Os dados foram tratados estatisticamente, sendo calculados os desvios padrões e realizada a análise de variância (ANOVA). Em seguida, as médias foram comparadas pelo teste de Tukey, ao nível de 5\% de significância, utilizando-se o programa SAS (SAS Institute, 1990).

A metodologia de superfície de resposta (Kruri \& Cornell, 1996) foi utilizada para avaliar a influência das variáveis na formulação de fishbúrguer. Os ensaios experimentais foram realizados de acordo com um planejamento fatorial $2^{2}$ completo, com 4 pontos fatoriais (níveis \pm 1 ), 4 pontos centrais (nível 0) e 4 pontos axiais $( \pm \alpha)$, totalizando 12 formulaçõ $(1,0$ e 1,0; 3,5 e 1,$0 ; 1,0$ e 2,$5 ; 3,5$ e 2,$5 ; 0,5$ e 1,$75 ; 4,0$ e 1,$75 ; 2,25$ e 0,$70 ; 2,25$ e 2,80 ; e quatro vezes de 2,25 e $1,75 \%$ de óleo de milho e fibra de trigo, respectivamente. Objetivou-se avaliar o efeito da quantidade de óleo de milho $(\mathrm{O})$ e fibra de trigo $(\mathrm{F})$ (variáveis independentes) sobre as respostas encolhimento (E) e capacidade de retenção de água $(\mathrm{C})$, ao final do processo. Os dados obtidos foram ajustados ao seguinte modelo matemático: $\mathrm{Y}=\varphi(\mathrm{E}, \mathrm{C})=\beta_{0}+\beta_{1} \mathrm{O}+\beta_{2} \mathrm{~F}+\beta_{11} \mathrm{O}^{2}+\beta_{22} \mathrm{~F}^{2}+\beta_{12}$ OF (Equação 1)

Em que: $\beta_{n}$ coeficientes de regressão, ${ }_{\mathrm{Y}}$ resposta em questão ( $\mathrm{E}$ e $\mathrm{C}$ ) $\mathrm{O}$ e $\mathrm{F}$ variáveis independentes codificadas (\% de óleo de milho e \% fibra de trigo).

Nesse processo, as respostas obtidas em todos os ensaios foram avaliadas quanto aos efeitos principais e às interações entre os fatores, em nível de $5 \%$ de significância, através do programa computacional Statistica 6.0 (Statsoft, 1997).

\section{RESULTADOS E DISCUSSÃO}

Verificou-se que a resposta referente ao menor percentual de encolhimento de $4,3 \%$ e a maior capacidade de retenção de água de $87 \%$ foi a da formulação 3 , com $1 \%$ de óleo de milho e $2,5 \%$ de fibra quando comparada às demais formulações (Tabela 1). Esses resultados apresentaram adequação à qualidade do produto final em face do valor reduzido de $4,3 \%$ de encolhimento. Esse valor foi bem menor do que os encontrados por Braga et al. (2010) pesquisando hambúrgueres de polpa de tilápia adicionados de amido e farinha de aveia, os quais encontraram valores de encolhimento de $14,51 \%$. A interação entre o óleo de milho e fibra de trigo sobre o percentual de encolhimento do fishbúguer foi positiva ao se utilizar $1 \%$ de óleo de milho, combinado com $2,5 \%$ de fibra de trigo, obteve-se melhor (menor) índice de encolhimento $(4,3 \%)$ do fishbúrguer. A equação utilizada ajustada obtida foi

$\mathrm{Y}_{(\mathrm{E})}=8,4443-1,4206 \mathrm{O}-0,5607 \mathrm{~F}-0,1524 \mathrm{O}^{2}+$ $1,24 \mathrm{OF}-0,6047 \mathrm{~F}^{2}$

$\mathrm{R}^{2}=0,868$

Em que: E \% de encolhimento; $\mathrm{O} \%$ de óleo de milho e $\mathrm{F} \%$ de fibra de trigo.

Foi verificado o efeito da interação entre o óleo de milho e a fibra de trigo na capacidade de retenção de água (CRA). O maior nível (87\%) foi obtido quando se adicionou a combinação de $1 \%$ de óleo de milho e de $2,5 \%$ de fibra de trigo. A equação que representa esse comportamento é:

$\mathrm{Y}_{(\mathrm{C})}=75,4675+2,6069 \mathrm{O}+8,6977 \mathrm{~F}-0,24390^{2}$ $1,8667 \mathrm{OF}-1,1312 \mathrm{~F}^{2}$

$\mathrm{R}^{2}=0,917$

Em que: $\mathrm{C}$ capacidade de retenção de água; $\mathrm{O} \%$ de óleo de milho e $\mathrm{F} \%$ de fibra de trigo.

O percentual de retenção de água verificado é de maior magnitude do que valores relatados para CRA em fishbúrgueres elaborados com polpa de tilápia, em que foram obtidos resultados para capacidade de retenção de água de 78,59\% sem efeitos na adição de amido de mandioca e de farinha de aveia sobre a CRA (BRAGA et al., 2010).

As CMS apresentaram padrões microbiológicos dentro do estabelecido na legislação vigente, RDC $\mathrm{N}^{0} 12$ da ANVISA (Brasil, 2001), para o Número Mais Provável (NMP) de coliformes termotolerantes e pesquisa de Escherichia coli (Tabela 2). Além disso, ressalta-se a importância dessa CMS não apresentar sob o aspecto microbiológico, níveis considerados contaminantes de alimentos, nas fases de manipulação e no preparo do produto final. Nesse sentido pode ser observado que o produto final apresenta características próprias para consumo humano. Esses resultados são semelhantes aos obtidos por Kirschnik \& Macedoviegas (2009), que analisaram CMS de tilápia. No entanto, diferem de resultados encontrados por MARENGONI et al., (2009), que detectaram E. coli em todas as amostras de CMS de tilápia analisadas.

$\mathrm{Na}$ pesquisa de Salmonella, todas as amostras de CMS analisadas apresentaram resultados negativos, resultados semelhantes aos encontrados no trabalho de Kirschnik \& Macedo-Viegas (2009) pesquisando CMS. Nesse sentido é importante salientar que a CMS em estudo praticamente não engloba essa espécie patogênica, indicando que o mesmo poderá ser consumido sem riscos de infecção alimentar. 
Tabela 1 - Respostas das variáveis dependentes de acordo com o planejamento fatorial da formulação de fishbúrguer de Carne Mecanicamente Separada (CMS) de tilápia do Nilo adicionado de fibra de trigo insolúvel e óleo de milho.
Ensaio
Variáveis independentes
Variáveis dependentes

\begin{tabular}{|c|c|c|c|c|c|c|}
\hline & \multicolumn{2}{|c|}{ Codificadas } & \multicolumn{2}{|c|}{ Decodificadas } & \multirow[b]{2}{*}{$\mathrm{E}(\%)$} & \multirow[b]{2}{*}{$\mathrm{C}(\%)$} \\
\hline & $\mathrm{O}$ & $\mathrm{F}$ & $\mathrm{O}(\%)$ & $\mathrm{F}(\%)$ & & \\
\hline 1 & -1 & -1 & 1 & 1 & 6,50 & 84 \\
\hline 2 & +1 & -1 & 3,5 & 1 & 4,70 & 83 \\
\hline 3 & -1 & +1 & 1 & 2,5 & 4,30 & 87 \\
\hline 4 & +1 & +1 & 3,5 & 2,5 & 7,15 & 79 \\
\hline 5 & $-1,41$ & 0 & 0,5 & 1,75 & 6,50 & 87 \\
\hline 6 & $+1,41$ & 0 & 4 & 1,75 & 6,20 & 81 \\
\hline 7 & 0 & $-1,41$ & 2,25 & 0,7 & 6,00 & 82 \\
\hline 8 & 0 & $+1,41$ & 2,25 & 2,80 & 6,30 & 85 \\
\hline 9 & 0 & 0 & 2,25 & 1,75 & 6,52 & 85 \\
\hline 10 & 0 & 0 & 2,25 & 1,75 & 6,62 & 84 \\
\hline 11 & 0 & 0 & 2,25 & 1,75 & 6,52 & 85 \\
\hline 12 & 0 & 0 & 2,25 & 1,75 & 6,42 & 84 \\
\hline
\end{tabular}

Tabela 2 - Análises bacteriológicas das CMS e dos fishbúrgueres de Carne Mecanicamente Separada (CMS) de tilápia do Nilo adicionado de fibra de trigo insolúvel e óleo de milho.

\begin{tabular}{|c|c|c|c|c|c|}
\hline Análises & $\begin{array}{c}\text { Coliformes } \\
\text { termotolerantes } \\
\text { NMP/g }\end{array}$ & $\begin{array}{l}\text { Pesquisa de } E \text {. } \\
\text { coli }\end{array}$ & $\begin{array}{c}\text { Contagem de } \\
\text { Estafilococos } \\
\text { coagulase positiva } \\
\text { UFC/g }\end{array}$ & $\begin{array}{l}\text { Pesquisa de } \\
\text { Salmonella }\end{array}$ & $\begin{array}{c}\text { Clostrídios sulfito } \\
\text { redutores } \\
\mathrm{NMP} / \mathrm{g}\end{array}$ \\
\hline \multirow[t]{4}{*}{$\overline{\mathrm{CMS}}$} & 21 & Negativa & $3,5 \times 10^{2}$ & Ausência & $<0,3$ \\
\hline & $<3,0$ & Negativa & $<0,3$ & Ausência & $<0,3$ \\
\hline & $<3,0$ & Negativa & $<0,3$ & Ausência & $<0,3$ \\
\hline & 240 & Negativa & $<0,3$ & Ausência & $<0,3$ \\
\hline \multirow[t]{4}{*}{ Fishbúrguer } & $<3,0$ & Negativa & $<0,3$ & Ausência & - \\
\hline & $<3,0$ & Negativa & $<0,3$ & Ausência & - \\
\hline & $<3,0$ & Negativa & $<0,3$ & Ausência & - \\
\hline & $<3,0$ & Negativa & $<0,3$ & Ausência & - \\
\hline
\end{tabular}

NMP - Número mais provável . UFC - Unidade formadora de colônia. 
Com relação aos clostrídios sulfito redutores, embora a legislação vigente não contemple produtos tipo surimi e similares à base de pescado, são exigidos para CMS de outras espécies. Para assegurar a segurança do produto, foram também realizadas contagens deste grupo de bactérias. Nesse âmbito, as CMS avaliadas apresentaram resultados similares, tanto para estafilococos como para Clostridium, aos encontrados por Gonzáles-Fandos et al. (2005) pesquisando estes micro-organismos em fatias de salmão.

Na Tabela 3 constam os resultados obtidos nas determinações físico-químicas das CMS. Os elevados teores de umidade da CMS de tilápia são provavelmente devido ao processo de lavagem para remover as proteínas hidrossolúveis, minerais e lipídios, resultando no aumento desses valores (GRYSCHEK, OETTERER \& GALLO, 2003). É importante salientar que valores de umidade em CMS lavadas podem diferir muito entre si, dependendo do processo de lavagem e da retirada de água utilizados. Os valores obtidos no presente trabalho são inferiores aos encontrados por Leyva-Mayorga et al. (2002), que pesquisando a composição centesimal de surimi fresco de tilápia do Nilo encontraram valores de umidade de $78,3 \%$. Com relação ao processo de lavagem, este poderá ou não ser utilizado dependendo do caso. Esse processo poderá melhorar a qualidade e outras características da $\mathrm{CMC}$, removendo o sangue, pigmentos, proteínas sarcoplasmáticas, componentes solúveis, substâncias de degradação, oxidação lipídica e coloração indesejável (KIRSCHNIK \& MACEDOVIEGAS, 2009). Por outro lado, independentemente da lavagem da CMS de tilápia, esta permanece estável e própria para o consumo durante 180 dias de armazenamento $\mathrm{a}-16^{\circ} \mathrm{C}$ (GRYSCHEK et al., 2003).

Os teores de proteínas encontrados nas CMS, de $13,02 \%$, estão de acordo com os estabelecidos na legislação vigente para CMS (Brasil, 2000a), que é de no mínimo $12 \%$. Os teores encontrados foram ligeiramente superiores aos encontrados por LeyvaMayorga et al. (2002), da ordem de 12\% em surimi. Provavelmente esse fato foi devido à remoção da maioria das proteínas solúveis sarcoplasmáticas, tendo sido também observado por outros autores, como Adu et al. (2003), que reportaram consideráveis perdas de proteína e outros componentes hidrossolúveis após o processo de lavagem de CMS de tilápia.

Os teores de lipídios, de $11,03 \%$, estão conforme permitido pela legislação, que pode ser de no máximo $30 \%$. Entretanto, os valores obtidos foram superiores aos obtidos por outros pesquisadores como Eymard et al. (2005), que obtiveram valores da ordem de 3,6\%, enquanto Gryschek, Oetterer \& Gallo (2003) detectaram 4,23\% pesquisando CMS de tilápia não lavadas.

A quantidade de cálcio presente na CMS enquadra-se nos valores citados na legislação pertinente, que é de no máximo $1,5 \%$ em base seca (BRASIL, 2000a).

Os fishbúrgueres apresentaram-se dentro dos padrões microbiológicos estabelecidos na RDC $\mathrm{N}^{0} 12$ da ANVISA (Brasil, 2001) para todos os microorganismos pesquisados (Tabela 2). Apesar da CMS ter apresentado elevada carga de coliformes termotolerantes, os fishbúrgueres estão dentro dos padrões da legislação, que estabelece até $10^{3} \mathrm{NNP} / \mathrm{g}$. Os condimentos e aditivos utilizados no processo foram suficientes para debelar estes micro-organismos (Marengoni et al., 2009) Para o NMP de coliformes termotolerantes e para pesquisa de Escherichia coli, estes resultados diferem dos encontrados por outros autores (Marengoni et al., 2009), que detectaram presença de E. coli em todas as amostras de fishbúrgueres analisadas.

Os resultados da contagem de estafilococos coagulase positiva estão dentro dos limites estabelecidos, apesar de uma das contagens ter sido elevada. Estes resultados são condizentes com os valores obtidos por Marengoni et al. (2009), ao pesquisar quatro diferentes formulações de fishbúrguer de CMS de tilápia. A pesquisa de Salmonella foi negativa em todas as amostras de fishbúrgueres, estando de acordo com a legislação vigente e com outras pesquisas realizadas em fishbúrgueres (KIRSCHNIK \& MACEDO-VIEGAS, 2009).

Tabela 3 - Resultados das análises físico-químicas da Carne Mecanicamente Separada e dos fishbúrgueres de (CMS) de tilápia do Nilo adicionado de fibra de trigo insolúvel e óleo de milho.

\begin{tabular}{lll}
\hline Amostras & CMS & Fishbúrguer \\
\hline Umidade & $72,75 \pm 1,31$ & $71,16 \pm 0,7$ \\
Proteínas & $13,02 \pm 0,3$ & $12,58 \pm 0,6$ \\
Cinzas \% & $1,08 \pm 0,3$ & $1,81 \pm 0,3$ \\
Lipídios $(\%)$ & $11,03 \pm 0,5$ & $9,2 \pm 0,24$ \\
Carboidratos $(\%)$ & $2,09 \pm 1,2$ & $5,1 \pm 0,9$ \\
Cálcio \% & $0,023 \pm 11,4$ & $0,036 \pm 11,7$ \\
Fibra bruta $(\%$ & $1,43 \pm 0,6$ & $2,19 \pm 0,38$ \\
pH & $6,29 \pm 0,1$ & $6,33 \pm 0,0$ \\
\hline
\end{tabular}

Resultados expressos como média \pm desvio padrão. 
Os resultados das análises físico-químicas para fishbúrgueres podem ser observados na Tabela 3. Os valores de umidade dos produtos da ordem de 70 a 72 $\%$ podem ser considerados superiores aos encontrados por Coelho et al., (2007) e semelhantes aos valores obtidos por Marengoni et al. (2009), quando foram avaliadas quatro formulações de fishbúrguer de polpa de tilápia.

Os teores de proteína são ligeiramente superiores aos encontrados por Coelho et al., (2007) que ao pesquisarem fishbúrgueres elaborados a partir de surimi de Merluccius hubsi encontraram teores de 10,6 a $11,8 \%$.

Um fato significativo são os valores obtidos para lipídios nos fishbúrgueres. Esses valores de cerca de 9,2 \% (Tabela 3), são inferiores aos estabelecidos na legislação para hambúrgueres de bovinos, suínos e aves, que é de $23 \%$ (BRASIL, 2000b), sendo então o produto considerado de teor de gordura reduzido, fato este benéfico ao consumidor. Com isso, esses resultados estão de acordo com o que é colocado por Jimenez-Colmenero et AL., (2001) de que com a inclusão de óleos vegetais na confecção do produto final, está também havendo uma redução do colesterol, de comprovadamente efeitos maléficos à saúde. Nesse sentido óleos de milho e de oliva devem ser utilizados em produtos tipo salsichas e similares.

Os teores de cálcio quantificados nos produtos representam valores inferiores aos preconizados pelo padrão de identidade e qualidade de hambúrgueres, que é de no máximo $0,1 \%$ em base seca para hambúrgueres crus (BRASIL 2000b).

A fibra bruta presente nos fishbúrgueres analisados variou de 1,81 a $2,57 \mathrm{~g} / 100 \mathrm{~g}$, com valor médio de 2,19 g/100 g (Tabela 3), resultados condizentes aos relatados por Clariant (2001), que afirmou que com apenas $1 \%$ de fibra de trigo é possível obter melhorias funcionais significativas em produtos cárneos. Assim, este resultado está em concordância com os resultados obtidos por Carbonel et al., (2005) de que o trigo influencia de forma positiva o processamento do produto, seu rendimento, redução do custo da formulação e principalmente a capacidade de retenção de água, que no caso da CMS de tilápia foi de $87 \%$, para a formulação selecionada (Tabela 1).O mais importante é que ao produto podem ser atribuídos os dizeres "contém fibras", o que é um apelo benéfico para uma classe de consumidores.

Os valores de $\mathrm{pH}$ descritos na Tabela 3, provavelmente foram decorrentes da utilização de polifosfato e eritorbato na elaboração dos fishbúrgueres, os quais alteraram os valores. Konno (1992) também verificou mudança no $\mathrm{pH}$ ao utilizar esses mesmos aditivos.

Os fishbúrgueres apresentaram luminosidade ( $\left.\mathrm{L}^{*}\right)$ de 61,69 $\pm 1,24$, intensidade da cor vermelha ( $\left.\mathrm{a}^{*}\right)$ de $1,88 \pm 0,30$ e intensidade da cor amarela $\left(b^{*}\right)$ de $19,44 \pm 0,51$. A tonalidade mais amarelada no fishbúrguer deve ter correlação com os condimentos utilizados. Provavelmente foi devido ao condimento noz moscada. É importante considerar também as variações da espessura do produto, bem como a cor da superfície na qual o produto foi analisado (SANCHEZ- ZAPATA et al., 2011)

Os resultados da ADQ (análise descritiva quantitativa) encontram-se descritos na Tabela 4. A avaliação final da ADQ foi realizada por oito julgadores treinados, que atribuíram notas a nove atributos (cor, uniformidade, aroma de peixe de água doce, aroma de condimentos, sabor de peixe de água doce, sabor de condimentos, maciez, suculência e avaliação global). Vale ressaltar que dentre as médias obtidas, o limite superior foi de 8,2 para suculência e o inferior foi de 5,6 para aroma de condimento. A média obtida para a avaliação global indica coerência entre os julgadores com relação a todos os atributos pesquisados.

Tabela 4 - Valores médios atribuídos pelos julgadores aos atributos da Análise Descritiva Quantitativa (ADQ) dos fishbúrgueres de Carne Mecanicamente Separada (CMS) de tilápia do Nilo adicionado de fibra de trigo insolúvel e óleo de milho

\begin{tabular}{lllc}
\hline Julgador & Média & DP & CV (\%) \\
\hline Cor & 6,9 & 0,56 & 4,43 \\
Uniformidade & 7,9 & 0,55 & 5,53 \\
Aroma de pad & 6,0 & 0,44 & 11,36 \\
Aroma de cond & 5,6 & 0,74 & 4,40 \\
Sabor pad & 7,8 & 0,45 & 5,20 \\
Sabor cond & 6,1 & 0,49 & 4,30 \\
Maciez & 8,1 & 0,41 & 3,20 \\
Suculência & 8,2 & 0,36 & 2,95 \\
Avaliação global & 7,0 & 0,32 & 205 \\
\hline
\end{tabular}

CV - Coeficiente de variação; DP - Desvio padrão; Pad = peixe de água doce. Cond. = condimentos; $\mathrm{N}$ de julgadores. 


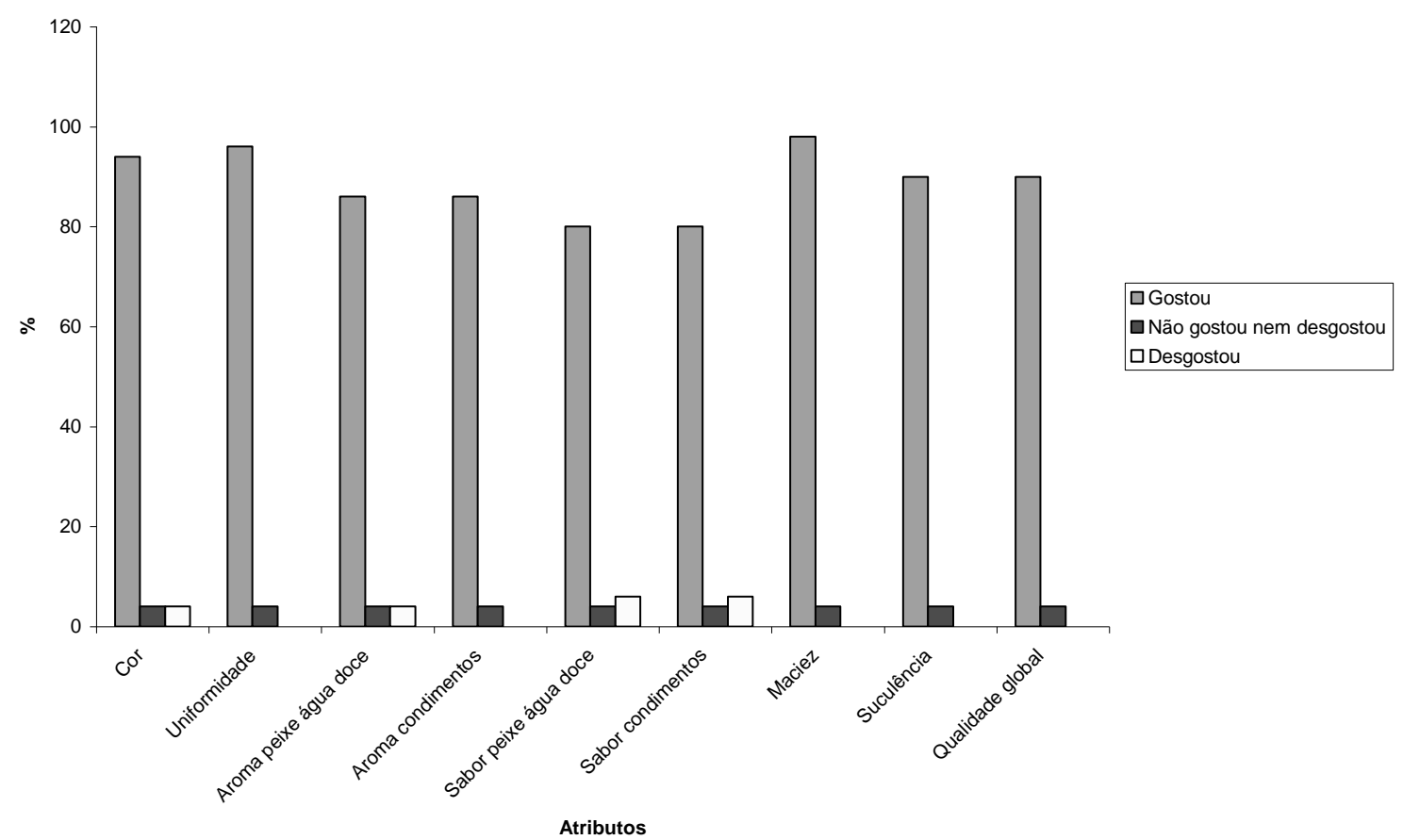

Figura 1 - Percentual de respostas dadas aos atributos pelos provadores para o teste de aceitação dos fishbúrgueres de Carne Mecanicamente Separada de tilápia do Nilo adicionado de fibra de trigo insolúvel e óleo de milho.

Em estudos sobre aceitação de consumidores foi indicado que a maciez da carne é freqüentemente o atributo mais importante na satisfação geral do consumidor (LAWRIE, 2005). Nesse contexto foi obtido para esta variável, o valor médio de 8,1 no fishbúrguer de tilápia (Tabela 4) que é considerado muito adequado. Valores similares também foram obtidos em fishbúrguer de tilápia por Tokur et al. (2004), que obtiveram média de 7,8 a 9,0 para os atributos de cor, odor, sabor, textura, avaliados por sete julgadores treinados.

A análise de ADQ é uma forma de identificar atributos importantes quando deseja-se desenvolver um novo produto. Um painel quando bem treinado possui acuidade sensorial e esse método permanece como o mais abrangente, fornecendo informações detalhadas sobre as propriedades dos produtos (Murray et al. 2001).

Os resultados obtidos para o teste de aceitação estão representados na Figura 1. Quando a aceitabilidade é superior a $70 \%$, considera-se que o produto pode ser inserido no comércio (TEIXEIRA et al., 1987). Os resultados obtidos foram superiores aos encontrados por Braga et al. (2010) que testaram quatro formulações de fishbúrgueres à base de polpa de tilápia para os atributos aroma, sabor, maciez, e cujas notas corresponderam a "gostei moderadamente".

No teste de atitude de compra, verificou-se que $84 \%$ dos provadores atribuíram notas que se encontram no intervalo de "compraria" a "possivelmente compraria", enquanto que 16\% "talvez comprasse" / "talvez não comprasse". Esses dados são semelhantes aos obtidos por Marengoni et al. (2009), ao pesquisarem intenção de compra de quatro formulações de fishbúrgueres de CMS de tilápia, obtendo resultados que variaram entre "possivelmente compraria o produto" a "talvez comprasse" / "não comprasse".

\section{CONCLUSÃO}

A grande aceitação sensorial é indicativa que a fibra de trigo e o óleo vegetal de milho podem ser utilizados na elaboração do produto. A adição do óleo de milho confere ao produto final maior adequação quanto à isenção de gordura animal. A adição de fibra de trigo alimentar aumenta a capacidade de retenção de água reduzindo a quantidade de óleo a ser utilizado sem prejuízo para a textura do produto.

Fishbúrgueres elaborados a partir de CMS de tilápia apresentam teores de lipídios correspondentes a uma terça parte dos teores permitidos pela legislação.

\section{AGRADECIMENTOS}

À Nutrassim pela fibra de trigo insolúvel. À Spel do Brasil pelos envoltórios cedidos para a elaboração das mortadelas, à Fuchs pelos condimentos e especiarias, à Tovani pela proteína isolada de soja e à Sunfoods pelo corante e aromas. Ao Laboratório de Avaliação Ponderal de Animais Aquáticos pela utilização dos equipamentos.

\section{REFERÊNCIAS}

ADU, G. A.; BABBITT, J. K.; CRAWFORD, D. L. Effect of washing on the nutritional and quality characteristics of dried minced rochfish flesh. Journal of Food Science, v.48, p.1053-1055, 1983. 
ARISSETO, A. P.; POLlONIO, M. A. R. Avaliação da estabilidade oxidativa do hambúrguer tipo calabresa, formulado com reduzidos teores de nitrito e diferentes percentagens de gordura, durante armazenamento congelado. Revista Higiene Alimentar, v.19, n.136, p.72-80, 2005.

ASCAR, J. M. Alimentos: aspectos bromatológicos e legais; análise percentual. São Leopoldo, RS: Unisinos Editora, 1985. 327p.

AOAC - Association of Official Analytical Chemists. Official methods of analysis. 18.ed. Washington, DC, 2006.

BRAGA, G. C.; PASQUETTI, T. J.; BUENO, G. W.; MERENGONI, N. G. Adição de amido e farinha de aveia na formulação de hambúrguer de polpa de tilápia-do-nilo (Oreochromis niloticus). 2010. Disponível em: <http://e-revista.unioeste.br/index.php/ scientiaagraria/article/view/2051/1622>. Acesso em: 15 jan. 2011.

BRASIL. Ministério da pesca e Aquicultuta. Brasília: Boletim estatístico da pesca e aqüicultura, 2012. 129p.

BRASIL. Ministério da Agricultura do Abastecimento e da Reforma Agrária. Secretaria de Defesa Agropecuária. Manual de métodos microbiológicos para alimentos. Brasília, 1992.136p.

BRASIL. Ministério da Agricultura, Pecuária e do Abastecimento. Regulamento técnico para fixação de identidade e qualidade de carne mecanicamente separada (cms) de aves, bovinos e suínos. Instrução Normativa $n^{\circ} 4$, de 31 março de 2000. Diário Oficial da União, Brasília, DF, 5 abr. 2000a.

BRASIL. Ministério da Agricultura e Abastecimento. Instrução Normativa $n^{\circ} 20$, de 31 julho de 2000. Anexo IV. Regulamento técnico de identidade e qualidade de hambúrguer. Diário Oficial da União, Brasília, DF, 3 ago. 2000 b.

BRASIL. Ministério da Agricultura, Pecuária e Abastecimento. Instrução Normativa $n^{\circ}$ 62, de 26 de agosto de 2003. Oficializa os métodos analíticos oficiais para análises microbiológicas para controle de produtos de origem animal e água. Diário Oficial da União, Brasília, DF, p.14, 18 set. 2003. Seção 1.

BRASIL. Ministério da Agricultura, Pecuária e do Abastecimento. Revisão RIISPOA. 8 jul. 2008. Disponível em: <http://www. agricultura.gov.br/ imagens/mapa/arq.portal/rispoa.pdf $>$. Acesso em: 2 nov. 2008.

CARBONELL, L. A.; FERNÁNDEZ-LÓPEZ, J.; PÉREZ-ALVAREZ, J. A.; KURI, V. Functional and sensory effects of fibre-rich ingredients on breakfast fresh sausages manufacture. Food Science and Technology International, v.11, n.2, p.89-97, 2005.
COELHO, G. M.; WESCHENFELDER, A. V.; MEINERT, E. M. Effects of starch properties on textural characteristics of fish burgers: sensory and Instrumental approaches. Boletim Centro de Pesquisas Alimentos, v.25, n.1, p.37-50, 2007.

CLARIANT INTERNATIONAL LTDA. Fibras insolúveis em produtos cárneos. São Paulo, 2001. 20p. Disponível em:<www.latam.clariant.com>. Acesso em: 10/06/2010.

EYMARD, S.; CARCOUET, E.; ROCHET, M. J.; DUMAY, J.; CHOPIN, C.; GENOT, C. Development of lipid oxidation during manufacturing of horse mackerel surimi. Journal of the Science of Food and Agriculture, v.85, p.1750-1756, 2005.

FIGUEREDO, O. V.; GASPAR, A.; BORGES, S. V.; DELLA MODESTA, R. C. Influence of animal fat substitutes on the quality of vienna type sausage. Brazilian Journal Food Technology, v.5, p.11-17, 2002.

FITZSIMMONS, K. Latest trends in tilapia production and market worldwide. In: CONGRESSO INTERNACIONAL DE AQUICULTURA, 2013, Rio de Janeiro. Disponível em: <http://www.infopesca.org/sites/default/files/ complemento/conferencias_eventos/documentos/919/O cultos//1.1Fitzsimmons.pdf >. Acesso em: 20 dez. 2013.

GLOBAL AQUACULTURE PRODUCTION. Global Outlook for Aquaculture Leadership, Bangkok, 2012. Disponível em: www.gaalliance.org/cmsAdmin/ upload.pdf. acessado em 07 de julho de 2013.

GONZÁLES-FANDOS, E.; VILLARINORODRIGUEZ, A.; GÁRCIA-LINARES, M. C.; GARCIA-ARIAS,M. T.; GARCIA-FERNANDES, M. $\mathrm{C}$ Microbiological safety and sensory characteristics of salmon slices processed by the sous vide method. Food Control, v.16, p.77-85, 2005.

GRYSCHEK, S. F. B.; OETTERER, M.; GALLO, C. R. Characterization and frozen storage stability of minced Nile tilapia (Oreochromis niloticus) and red tilapia (Oreochromis spp.). Journal os Aquatic Food Product Techology, v.12, n.3, p.57-69, 2003.

HAMM, R. Biochemistry of meat hydratation. Advances in Food Research, v.10, n.2, p.335-443, 1960.

JIMÉNEZ-COLMANERO, F.; CARBALLO, J.; COFRADES, S. Heathier meat and meat products: their role as functional foods. Meat Science, v.59, p.5-3, 2001.

KIRSCHNIK, P. G.; MACEDO-VIEGAS, E. M. Efeito da lavagem e da adição de aditivos sobre a estabilidade de carne mecanicamente separada de tilápia do Nilo (Oreochromis niloticus) durante estocagem a $-18{ }^{\circ} \mathrm{C}$. Ciência e Tecnologia Alimentos, v.29, n.1, p.200-206, 2009. 
KONNO, K. Suppression of thermal denaturation of miosin subfragment-1 of Alaska Pollack by sorbitol and accelerated inactivation by pyrophosphate. Journal Food Science, v.57, n.2, p.261-264, 1992.

KUHN, C. R.; SOARES, G. J. D. Proteases e inibidores no processamento de surimi. Revista Brasileira de Agrociência, v.8, n.1, p.5-11, 2002.

LEONHARDT, J. H.; CAETANO FILHO, M.; FROSSARD, H.; MORENO, A. M. Características morfométricas, rendimento e composição do filé de tilápia do Nilo, Oreochromis niloticus, da linhagem tailandesa, local e do cruzamento de ambas. Semina: Ciências Agrárias, v.27, n.1, p.125-132, 2006.

LEYVA-MAYORGA, M. A. L.; RAMIREZ, J. A.; POLO, M. O. M. Empleo de surimi liofilizado em emulsiones cárnicas com baja contenido em grasa. Ciência y Tecnologia de Alimentos, v.3, n.5, p.288-294, 2002.

MANSOUR, E. H.; KHALIL, A. H. Characteristics of low-fat beefburger as influenced by various types of wheat fibres. Food Research International, v.30, n.34, p.199-205, 1997.

MARENGONI, N. G.; POZZA, M. S. S.; BRAGA, G.; LAZZERI, D. B.; CASTILHA, L. D.; BUENO, G. W.; PASQUETTI, T. J.; POLESE, C. Caracterização microbiológica, sensorial e centesimal de fishburgers de carne de tilápia mecanicamente separada. Revista Brasileira de Saúde Produção Animal, v.10, n.1, p.168-176, 2009.

MOREIRA, R. T.; LEMOS, A. L. S. C.; MENDES, E. S.; HONÓRIO, Y. F.; GUIMARÃES, J. L.; CRISTIANINI, M. Caracterização microestrutural de embutido emulsionado de tilápia (Oreochromis nilótico). Braz. J. Food. Technol., v.9, n.3, p.22172221, 2006.

MURRAY, J. M.; DELAHUNT, C. M.; BAXTER, I. A. Descriptive sensory analysis: past, present and future. Food Research International, v.34, p.461-471, 2001.
SÁNCHEZ-ZAPATA, E.; FUENTES-ZARAGOZA, E.; NAVARRO-RODRÍGUEZ DE VERA, C.; SAYAS, E.; SENDRA, E.; FERNÁNDEZ-LÓPEZ, J.; PÉREZALVAREZ, J.A. Effects of tuna pâté thickness and background on CIEL*a*b* color parameters and reflectance spectra. Food Control, v.22, p.1226-1232, 2011.

SAS. The SAS System for Windows release version: 6.8, 3.ed. Cary: 1998, CD-ROM.

SIMÕES, D. R. S.; QUEIROZ, M. I.; VOLPATO, G.; ZEPKA, L. Q. Desodorización de la base proteica de pescado (bpp) con ácido fosfórico. Ciência e Tecnologia Alimentos, v.24, n.1, p.23-26, 2004.

STONE, L.; SIDEL, J.L. Quantitative descriptive analisys: developments, applications, and the future. Food Technology, v.52, n.8, p.48-52, 1998.

SUSSEL, F. R. Tilapicultura no Brasil e entraves na produção. Disponível em: www.ftp.sp.gov/ftpesca/ tilapiculturaEntraves 2013.pdf. Acesso em 20 dez. 2013.

TEIXEIRA, E.; MEINERT, E. M.; BARBETTA, P. A. Análise sensorial de alimentos. Florianópolis: UFSC, 1987. $180 \mathrm{p}$.

TOKUR, B.; POLAT, A.; BEKLEVIK, G.; ÖZKÜTÜK, S. Changes in the quality of fishburger produced from Tilapia (Oreochromis niloticus) during frozen storage $(-18 \mathrm{C})$. European Food Research Technology, v.218, p.420-423, 2004.

VIEGAS, E. M.; OLIVEIRA, P. R. CMS de tilápia na elaboração de salsichas. Revista. Aquicultura e Pesca, v.33, p.36-42, 2008.

WILD, M. B. Produtividade comercial em sistemas de reprodução de tilápia do Nilo da linhagem gift. Universidade Estadual do oeste do Paraná-UNIOESTE, 2013. 51p. Dissertação de Mestrado, Marechal Cândido Rondon. 